\title{
A Novel Dietary Protocol for Functional Bowel Disorders
}

\section{Fandi Ibrahim* and Philippa Stribling \\ Nutrition and Human Health, Life Sciences Directorate, University of Suffolk, Ipswich, United Kingdom}

Functional bowel disorders of various forms affect up to $30 \%$ of the population worldwide. Uncertainties still remain regarding the dietary management of such disorders, and the identification of foods or food ingredients implicated in symptom onset is often a challenging task. Individuals are normally living with chronic constipation, diarrhoea, or an alternation of both, bloating, excessive gas production, bowel urgency, straining, incomplete defecation, and abdominal pain. The severity of these symptoms varies among individuals, with a diverse impact on quality of life. Dietary approaches designed to help the sufferers are limited, with the most commonly used being the gluten-free diet and the low FODMAP diet. These approaches have various limitations, including the complexity and confusion associated with following the low FODMAP diet, and concerns regarding long-term nutritional adequacy, safety, and effectiveness.

Therefore, this study aimed to investigate the efficacy of an alternative dietary approach, named the 5Ad Dietary Protocol, in reducing the gastrointestinal symptoms of those living with functional bowel disorders. The protocol uses a complementary, nutritionally adequate, and minimally processed selection of foods in a modified paleo-style diet, and represents a balanced and healthy diet in its macronutrient and micronutrient composition. Stool consistency, stool frequency, and a Food Intolerance Index (0-100) were used to evaluate the efficacy of the proposed dietary protocol in a repeated measures design (baseline week and intervention week).

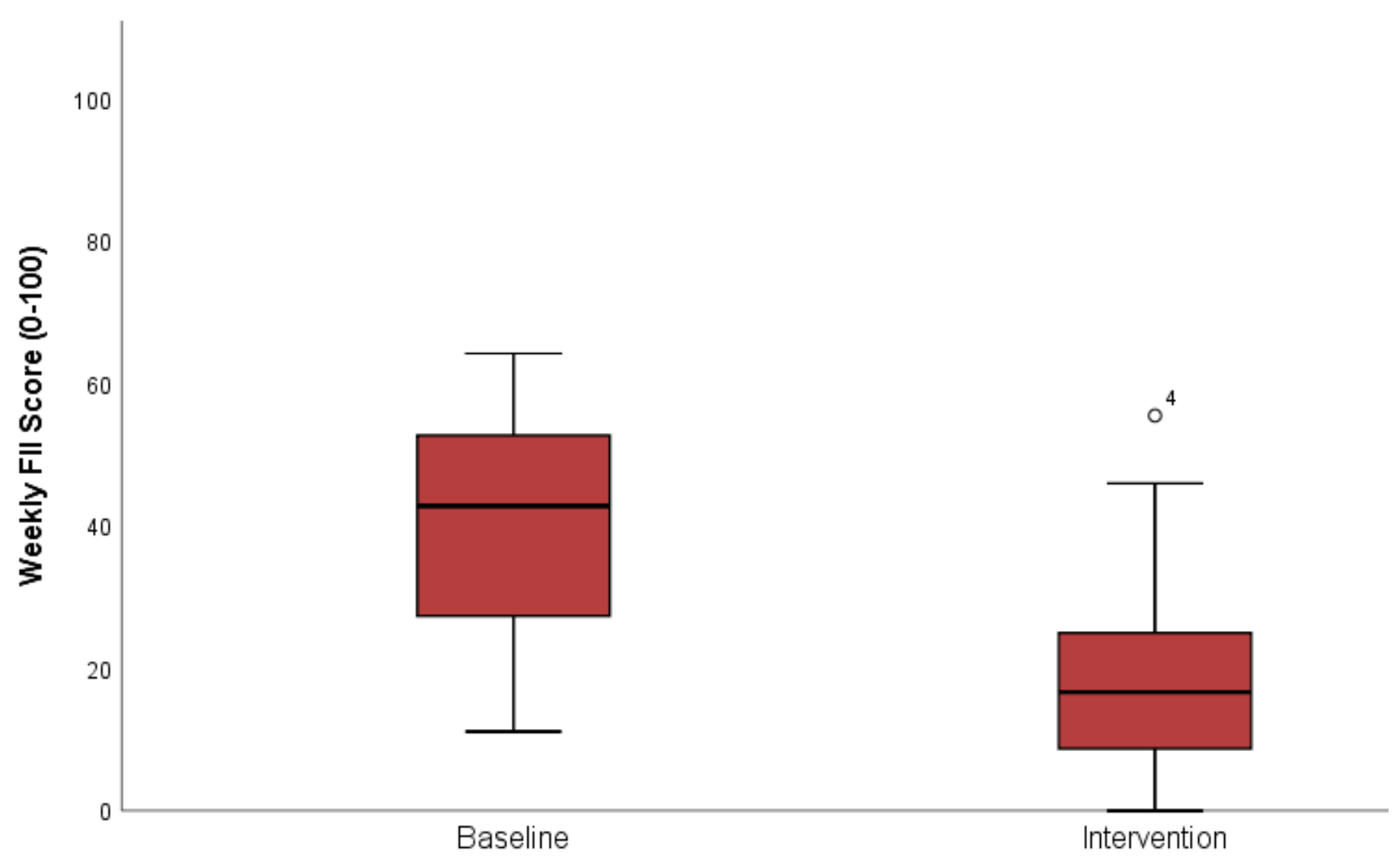

Figure 1. Food Intolerance Index (FFI) changes from baseline to intervention
The proposed Food Intolerance Index is a combined score of the severity of flatulence, bloating, abdominal pain, straining, incomplete defecation, and bowel urgency as recorded by the subjects using symptom diary forms. Fifteen participants completed this study (Table 1), and the Food Intolerance Index was significantly improved from baseline to intervention (39.6 \pm 4.6 to $16.7 \pm 3.7$, p-value $<0.001$, Figure 1 ). Additionally, the Bristol Stool Scale score also showed significant enhancement, with the direction depending on the baseline stool type (2.1 \pm 0.27 to $3.6 \pm 0.30$ for constipated subjects and $4.7 \pm 0.20$ to $4.3 \pm 0.41$ for subjects with baseline diarrhoea type), and a similar trend was observed for the weekly frequency of defection (from $3.5 \pm 0.87$ to $9.3 \pm 4.07$ and from $16.0 \pm 2.11$ to $11.4 \pm 1.80$, respectively).

The current evidence, and the positive feedback received from the participants, invites future research into the utility of the 5Ad Dietary Protocol, not only for functional bowel disorders, but also for inflammatory bowel disease and, potentially, extra-intestinal chronic diseases which are mediated through gut barrier functions.

\begin{tabular}{|c|c|}
\hline $\begin{array}{l}\text { Age range } \\
(\text { mean } \pm S E)\end{array}$ & $\begin{array}{c}33-69 \\
(48.14 \pm 3.04)\end{array}$ \\
\hline $\begin{array}{c}\text { Gender } \mathrm{n},(\%) \\
\text { Females } \\
\text { Males }\end{array}$ & $\begin{array}{c}10,(67 \%) \\
5,(33 \%)\end{array}$ \\
\hline $\begin{array}{c}\text { BMI category } \mathrm{n},(\%) \\
\begin{array}{c}18.5-24.9 \mathrm{~kg} / \mathrm{m}^{2} \\
25-29.9 \mathrm{~kg} / \mathrm{m}^{2} \\
\geq 30 \mathrm{~kg} / \mathrm{m}^{2}\end{array}\end{array}$ & $\begin{array}{l}7,(47 \%) \\
5,(33 \%) \\
3,(20 \%)\end{array}$ \\
\hline $\begin{array}{l}\text { PAL n, (\%) } \\
\text { Inactive } \\
\text { Active }\end{array}$ & $\begin{array}{c}2,(14 \%) \\
13,(86 \%)\end{array}$ \\
\hline $\begin{array}{c}\text { IBS diagnosed n, (\%) } \\
\text { Yes } \\
\text { No } \\
\end{array}$ & $\begin{array}{l}6,(40 \%) \\
9,(60 \%)\end{array}$ \\
\hline $\begin{array}{c}\text { Baseline average stool type } \mathrm{n},(\%) \\
\text { Constipation (type 1-2) } \\
\text { Normal (type 3-4) } \\
\text { Diarrhoea (type 5-7) }\end{array}$ & $\begin{array}{l}6,(40 \%) \\
3,(20 \%) \\
6,(40 \%)\end{array}$ \\
\hline $\begin{array}{l}\text { Baseline defecation frequency } \mathrm{n},(\%) \\
\qquad 7 \text { times per week } \\
7 \text { times per week } \\
>7 \text { times per week }\end{array}$ & $\begin{array}{l}4,(27 \%) \\
2,(13 \%) \\
9,(60 \%)\end{array}$ \\
\hline
\end{tabular}

References

> Drossman, D.A. (2016) 'Functional Gastrointestinal Disorders: History, Pathophysiology, Clinical Features, and Rome IV', Gastroenterology, 150(6), pp.1262-1279

Enck, P., et al. (2016) 'Irritable bowel syndrome', Nature Reviews. Disease Primers, 2:16014

Öhman, L., Törnblom, H. and Simrén, M. (2015) 'Crosstalk at the mucosal border: importance of the gut microenvironment in IBS', Nature Reviews Gastroenterology \& Hepatology, 12(1), pp.36-49

Schmulson, M.J. and Drossman, D.A. (2017) 'What is New in Rome IV', Journal of Neurogastroenterology and Motility, 23(2), pp.151-163

Shepherd, S.J., Lomer, M.C. and Gibson, P.R. (2013) 'Short-chain carbohydrates and functional gastrointestinal disorders', The American Journal of Gastroenterology, 108(5), pp.707-717 